\title{
Formation of welding residual stresses in low transformation temperature (LTT) materials
}

\section{(Tensões Residuais de Soldagem em Materias de Baixa Temperatura de transformação (BTT))}

\author{
Thomas Kannengiesser ${ }^{l}$, Arne Kromm ${ }^{1}$, \\ ${ }^{1}$ Federal Institute for Materials Research and Testing (BAM), Unter den Eichen 87, 12205 Berlin, Germany \\ e-mail: Thomas.Kannengiesser@bam.de
}

\begin{abstract}
For the safety and cost efficiency of welded high-strength steel structures, precise knowledge of the level and distribution of weldingand cooling-specific stresses and residual stresses is essential, since they exert a decisive influence on strength, crack resistance, and finally on the bearable service load. This paper presents innovative filler materials, of which the phase transformation temperature was deliberately adjusted via the chemical composition. The transformation behaviour of these martensitic Low Transformation Temperature (LTT-) filler materials shows direct effects on the local residual stresses in the weld and the HAZ. These effects can purposefully be exploited to counteract the thermally induced shrinkage of the material and to produce significant compressive residual stresses in the weld. Comparative welding experiments were carried out on $690 \mathrm{MPa}$ high-strength base materials using various LTT-filler materials. High energy synchrotron radiation was used for residual stress measurement. Particularly the use of high energy synchrotron radiation makes it possible to detect the residual stress condition fast without destruction of material. Thereby, residual stress depth gradients can be determined simultaneously without removing material. In steel, gradients of up to $150 \mu$ m can be resolved in such a way. Furthermore, the application of high energy radiation permits determination of residual stresses of any available residual austenite contents. Results show significant dependence of transformation temperatures on the resulting residual stress level and distribution.
\end{abstract}

Key-words: Phase specific residual stresses; phase transformation; Low Transformation Temperature filler wire; energy dispersive diffraction; high strength steel.

Resumo: Para a segurança e eficiência do custo de estruturas soldadas de aço de alta resistência, um conhecimento preciso do nível e distribuição das tensões residuais de soldagem é essencial pois estas exercem uma influência decisiva na resistência à fissuração e na carga suportada em serviço. Este artigo apresenta metais de adição inovativos nos quais a temperatura de transformação foi deliberadamente ajustada pela composição química. A transformação destes metais de adição martensíticos causa um efeito direto nas tensões residuais nas zonas fundida e afetada pelo calor (ZAC). Estes efeitos são explorados para contrabalancear a contração térmica do material e produzir tensões residuais compressivas na solda. Testes comparativos de soldagem foram feitos em um metal base de alta resistência de $690 \mathrm{MPa}$ usando diferentes metais de adição de BTT. Radiação sincrótona de alta energia foi usada para medir as tensões residuais. O uso desta radiação permite medir as tensões rapidamente e de forma não destrutiva. Os resultados mostram uma dependência significativa da temperatura de transformação no nível e distribuição das tensões residuais resultantes.

Palavras-chave: Tensões residuais, transformação de fase, baixa temperatura de transformação, metal de adição, difração, aço de alta resistência.

\section{Introduction}

Safety of welded higher-strength steel structures calls for precise knowledge of the welding residual stresses which profoundly influence the crack resistance and the service load. The fact that the filler material, apart from constructional design and purposeful heat control, may contribute significantly to residual stress reduction is reflected in the studies conducted by [1-4] concerning the development of a high-strength filler material with correspondingly lowered martensitic transformation temperature (Low Transformation Temperature (LTT) filler material). First investigations into the effect of this filler material

(Recebido em 03/08/2008; Texto Final em 18/12/2008). on the welding residual stresses were recently carried out also by [5-8]. However, so far no concrete quantifications of residual stress distributions in welded butt joints are available.

This welding residual stress reduction due to low phase transformation temperatures can in principle be explained in the following way. Since the thermal expansion coefficient of austenite is higher than that of ferrite, volume expansion due to the phase transformation at low temperatures is higher. Following Bhadeshia [9], high shrinkage compensation of the fcc lattice $\left(R_{e} \Downarrow\right)$ during cooling, and hence lower stress rise, must additionally be assumed, since the evolution of higher stress is limited by the shrinkage due to the lower yield point of austenite compared to ferrite. In the bcc lattice $\left(\mathrm{R}_{\mathrm{e}} \Uparrow\right)$, by contrast, shrinkage compensation is lower involving comparably high stress gradients. Francis et al. [10] reported that displacive transformation from austenite into martensite gives higher 
volume change compared to reconstructive transformation of ferrite or pearlite due to a dilatation normal and a large shear strain component parallel to the habit plane in case of displasive transformation. Also, displacive transformation at low temperatures favours crystollagraphic variant selection due to higher acting stresses at these temperatures, leading to a transformation texture and anisotropic dimensional changes from what larger stress reductions can be expected. Furthermore, the finish temperature of the transformation is important hence subsequent thermal contraction gives rise to tensile stresses again.

For these reasons, minimizing of the residual stresses during welding is essential, i.e. lowest possible transformation temperatures have to be realized via alloy concepts with respective weldability, apart from heat control during welding (cooling rate). The use of higher-strength filler materials with correspondingly lowered martensitic transformation temperature may finally have positive effects also on the cold cracking resistance, as for example with the help of $\mathrm{M}_{\mathrm{f}}$-temperatures below room temperature with respective proportions of retained austenite.
The investigations carried out in this study using innovative high-strength filler materials with specifically lowered $M_{s} / M_{f-}$ temperatures have demonstrated that different transformation temperatures may significantly affect the welding residual stresses. In order to characterize the effect of lowered martensite start temperatures on the welding residual stresses, it was possible for the first time to apply high-energy synchrotron radiation. In this analysis, differentiation was made between the phase-specific residual stresses in the martensitic and austenitic phase.

\section{Experimental}

\subsection{Material}

Investigations in this work focused on three selected LTT filler materials with variation of the nickel content between $8 \%$ and $12 \%$ in steps of $2 \%$. Table 1 shows the nominal composition of LTT welding material and their $\mathrm{M}_{\mathrm{s}}$ - temperatures determined by thermal analysis as presented in [11].

Table 1. Nominal composition of weld metal and $\mathrm{M}_{\mathrm{s}}-$ temperatures.

\begin{tabular}{|c|c|c|c|c|c|c|}
\hline \multirow{2}{*}{$\begin{array}{c}\text { LTT filler } \\
\text { No. }\end{array}$} & \multicolumn{5}{|c|}{ Alloying elements in weld metal in Wt.\% } & \multirow{2}{*}{$\begin{array}{c}\mathrm{M}_{\mathrm{s}} \text { - temperatures } \\
\text { in }{ }^{\circ} \mathrm{C}[11]\end{array}$} \\
\cline { 2 - 6 } & $\mathrm{C}$ & $\mathrm{Ni}$ & $\mathrm{Cr}$ & $\mathrm{Mn}$ & $\mathrm{Si}$ & 184 \\
\hline 1 & 0.04 & 8 & 10 & 0.7 & 0.4 & 90 \\
\hline 2 & 0.04 & 10 & 10 & 0.7 & 0.4 & 39 \\
\hline 3 & 0.04 & 12 & 10 & 0.7 & 0.4 & \\
\hline
\end{tabular}

Table 2 represents the chemical compositions of the investigated welds measured by spark source spectroscopy. A slight decrease in chromium and nickel content compared to the nominal composition was found. In contrast, the weld metal experiences manganese and above all carbon dilution. These changes should barely have any effect on the $\mathrm{M}_{\mathrm{s}}$ - temperature and, hence, the decrease in nickel and chromium is balanced by dilution of carbon which strongly influences the $\mathrm{M}_{\mathrm{s}}$ - temperature.

Table 2. Chemical composition of weld metal in as welded condition.

\begin{tabular}{|c|c|c|c|c|c|}
\hline \multirow{2}{*}{ LTT No. } & \multicolumn{5}{|c|}{ Alloying elements in weld metal in wt.\% } \\
\hline & $\mathrm{C}$ & $\mathrm{Ni}$ & $\mathrm{Cr}$ & $\mathrm{Mn}$ & $\mathrm{Si}$ \\
\hline 1 & $\begin{array}{c}0.07 \\
(+0.03)\end{array}$ & $\begin{array}{c}7.33 \\
(-0.67)\end{array}$ & $\begin{array}{c}9.52 \\
(-0.48)\end{array}$ & $\begin{array}{c}1.05 \\
(+0.35)\end{array}$ & $\begin{array}{c}0.45 \\
(+0.05)\end{array}$ \\
\hline 2 & $\begin{array}{c}0.06 \\
(+0.02) \\
\end{array}$ & $\begin{array}{c}9.44 \\
(-0.56) \\
\end{array}$ & $\begin{array}{c}9.57 \\
(-0.43) \\
\end{array}$ & $\begin{array}{c}1.05 \\
(+0.35) \\
\end{array}$ & $\begin{array}{c}0.45 \\
(+0.05) \\
\end{array}$ \\
\hline 3 & $\begin{array}{c}0.08 \\
(+0.04)\end{array}$ & $\begin{array}{c}10.81 \\
(-1.19)\end{array}$ & $\begin{array}{c}9.19 \\
(-0.81)\end{array}$ & $\begin{array}{c}1.00 \\
(+0.3)\end{array}$ & $\begin{array}{c}0.40 \\
(+0.00)\end{array}$ \\
\hline
\end{tabular}

With respect to the intended application for high-strength joints, the high-strength fine-grained structural steel S690Q was used as base material. The chemical composition and the mechanical properties are presented in Table 3 and Table 4.

Table 3. Chemical composition of base material S690Q.

\begin{tabular}{|c|c|c|c|c|c|c|c|c|c|c|}
\hline \multicolumn{10}{|c|}{ Alloying elements of S690Q in wt.\% } \\
\hline $\mathrm{C}$ & $\mathrm{Si}$ & $\mathrm{Mn}$ & $\mathrm{P}$ & $\mathrm{S}$ & $\mathrm{Cr}$ & $\mathrm{Ni}$ & $\mathrm{Mo}$ & $\mathrm{Nb}$ & $\mathrm{V}$ & $\mathrm{B}$ \\
\hline 0.116 & 0.402 & 1.52 & 0.017 & $<0.001$ & 0.498 & 0.481 & 0.111 & $<0.005$ & 0.054 & 0.0005 \\
\hline
\end{tabular}

Table 4. Mechanical properties of base material S690Q.

\begin{tabular}{|c|c|c|}
\hline Tensile strength $\mathrm{R}_{\mathrm{m}}$ & Yield strength $\mathrm{R}_{\mathrm{p} 02}$ & Elongation \\
\hline $770-940 \mathrm{MPa}$ & $690 \mathrm{MPa}$ & $14 \%$ \\
\hline
\end{tabular}




\subsection{Welding Parameters}

Weld coupons were manual metal arc welded (MMAW) in 2 layers using the welding parameters provided in Table 5. After finishing the root run, this run was cooled down to room temperature in order to assure complete transformation into martensite. Subsequently, the final run was welded and cooled down under the same conditions. The welds were produced under free external shrinkage according to figures 1 and 2 .

Table 5. Welding parameters for MMA-welding.

\begin{tabular}{|c|c|}
\hline Welding current & $87 \mathrm{~A}$ \\
\hline Welding voltage & $26 \mathrm{~V}$ \\
\hline Travel speed & $2 \mathrm{~mm} / \mathrm{s}$ \\
\hline Heat input & $1 \mathrm{~kJ} / \mathrm{mm}$ \\
\hline
\end{tabular}

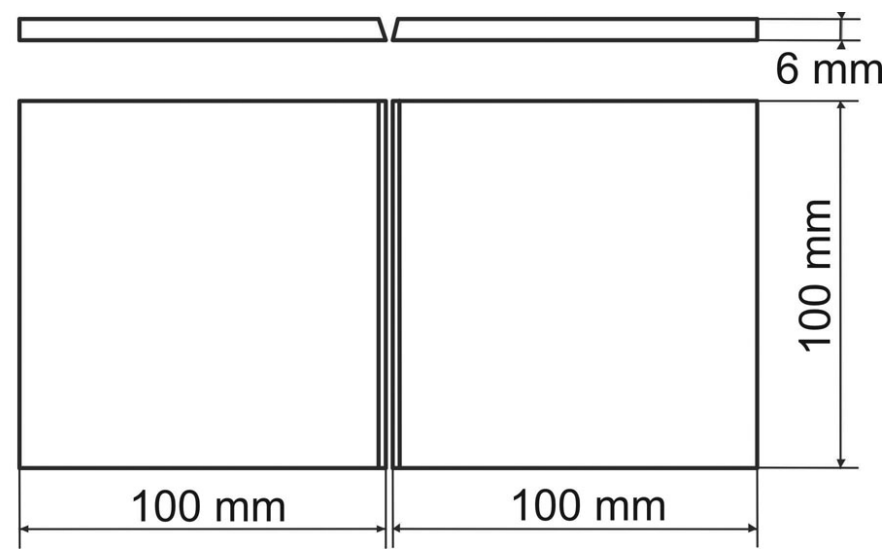

Figure 1. Weld coupon geometry.

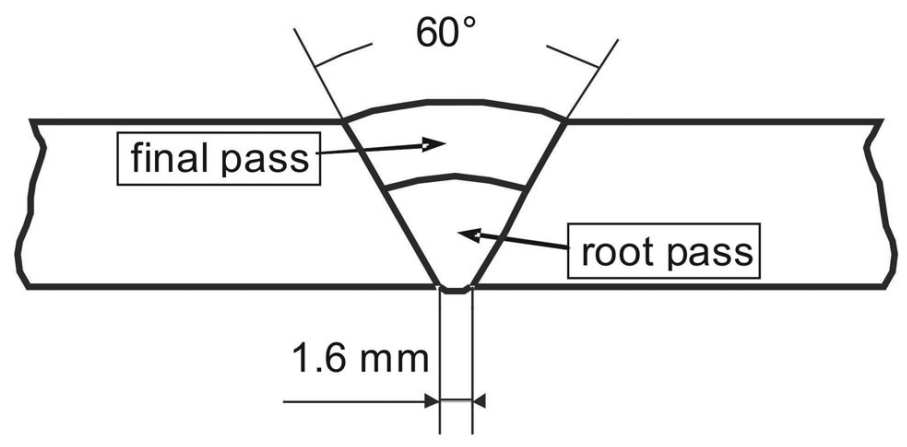

Figure 2. Joint geometry.

\subsection{Residual Stress Analysis}

The investigations by means of high energy synchrotron diffraction were carried out at the materials science beamline EDDI of the Hahn-Meitner-Institute Berlin (HMI) (as described in [12]) at the storage ring BESSY. High energy diffraction with a photon energy range from $20 \mathrm{keV}$ up to $150 \mathrm{keV}$ (white beam) enables fast recording of complete spectra of different crystalline phases at fixed positions in one experiment. In the present case, the residual stress analysis by means of energy dispersive diffraction was carried out in reflection mode. At energy dispersive diffraction the relation between the lattice spacing $d_{h k l}$ and the corresponding diffraction $E_{h k l}$ is given by inserting the relation:

$E=\frac{h \cdot c}{\lambda}$

(E - Energy, $\mathrm{h}$ - Planck's constant, $\mathrm{c}$ - velocity of light, $\lambda$ wavelength)

in Bragg's law:

$$
d_{h k l}=\frac{h \cdot c}{2 \cdot \sin \Theta_{d}} \cdot \frac{1}{E_{h k l}}=\text { const } \cdot \frac{1}{E_{h k l}}
$$

( $\mathrm{d}_{\mathrm{hkl}}-$ lattice spacing, $\Theta_{\mathrm{d}}-$ fixed diffraction angle)

In contrast to angle dispersive diffraction which is the conventional set-up for X-ray stress analysis using laboratory $\mathrm{X}$-ray sources, the main advantage of energy dispersive diffraction is that always a multitude of diffraction lines within the available energy range is recorded simultaneously by a suitable detector system. Stress analysis by means of energy dispersive diffraction allows to assign the measured diffraction lines to different information depths. Residual stress depth distribution can be determined that way (see e.g. [12-14]). For the stress analysis of the welded joints also robust average values of the residual stress measures will be presented here. The average stresses for the individual phases are calculated taken into account all measured interference lines of the corresponding phase whilst the residual stress values determined for each $\{\mathrm{hkl}\}$-lattice plane family are weighted by their multiplicity factor. Since the diffraction information from higher photon energies at a place $\mathrm{x}$ stem from depths of up to $100 \mu \mathrm{m}$, a plane stress condition cannot be assumed furthermore. Those residual stresses specified in the following thus represent surface parallel stresses minus possible normal stresses.

$\sigma(x)=\sigma_{11, \text { long }}-\sigma_{3}$ and $\sigma_{2, \text { trans }}-\sigma_{3}$

The residual stress depth distributions also shown in this work refer to the mean penetration depth $\tau$ of the radiation in accordance with $\tau=1 / 2\left(\tau_{\max }+\tau_{\min }\right)$ for the respective diffraction lines. Each diffraction line is assigned to a an average information depth $\tau$. The higher the photon energy, the higher is the information depth. This possibility was utilized for the analysis of the residual stress states after welding at selected measuring points in the weld. Stress analysis was carried out in the martensitic phase as well as in the austenitic one, which coexists in the weld zone next to the martensitic phase. Measuring parameters are shown in Table 6.

Measuring was performed across the weld at the centre of the specimen. Figure 3 indicates the measuring range and the measuring directions schematically. The well known $\sin ^{2} \psi$ -method for X-ray stress analysis was used for determination of longitudinal as well as transverse residual stresses. 
Table 6. Measuring and evaluation parameters.

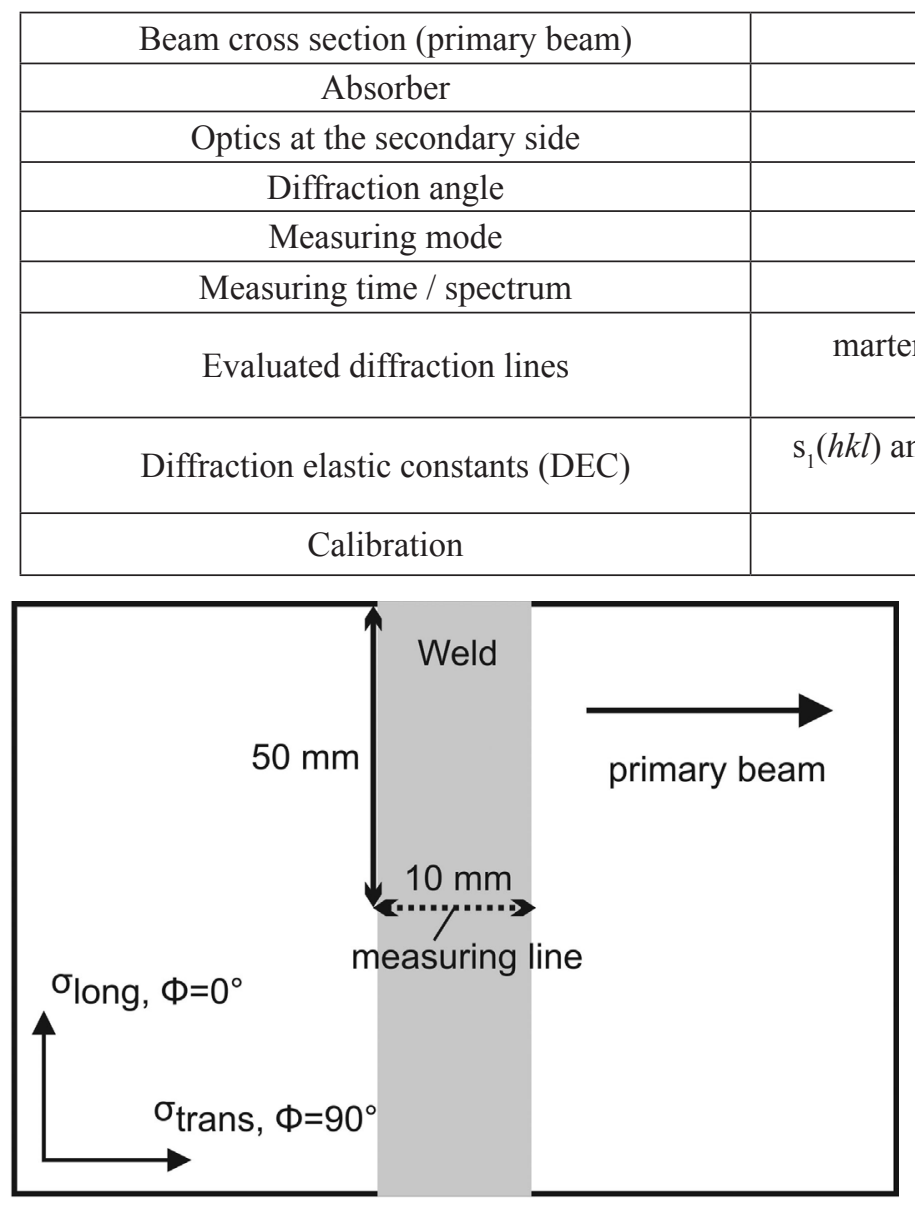

Figure 3. Measuring range and directions on specimen.

\section{Results and Discussion}

The residual stresses determined in the following for each case represent phase specific stresses which consist of residual stresses of I. order (macrostresses) and II. order (mean values of homogeneous microstresses). Equation (1) shows the relation:

$\bar{\sigma}^{\alpha}=\left\langle\sigma^{I}+\sigma^{I}\right\rangle^{\alpha}$

In the following diagrams, the phase specific residual stresses of the martensitic and the austenitic phase over the weld are represented for the three investigated LTT welding materials. Overall it becomes clear that compared to commercial highstrength filler materials, for which specifically in the HAZ high tensile residual stresses of, for example, more than $800 \mathrm{MPa}$ must be expected, LTT-filler materials lead to a significant reduction of the residual stress level.

The longitudinal residual stresses, of the martensitic phase (figure 4) of all three welding materials show a distribution as it is typical for transformation-affected welds. Therefore, transformation-associated compressive residual stresses were found at a distance of $3 \mathrm{~mm}$ from the weld centre, which change into minor tensile residual stresses at the weld centre due to quenching effects. The quenching occurred between surface and

$$
1 \times 1 \mathrm{~mm}^{2}
$$

$2 \mathrm{~cm}$ graphite

Double slit system (equatorial $\times$ axial) $0.03 \times 5 \mathrm{~mm}^{2}$

$2 \Theta=14^{\circ}$

Symmetrical $\Psi$ - mode (reflexion), $\psi=0^{\circ} \ldots 80^{\circ}$

$100 \mathrm{~s}$

: $110,200,211,220,310,222,321,330 / 411,420,431 / 510$

austenite: 111, 200, 220, 311, 222, 400, 331, 420

the Eshelby/Kröner-model

Tungsten powder, measured under similar conditions

core regions with a temporally shifted transformation. This gives rise to the development of tensile residual stresses within the surface as compensation for last developed compressive residual stresses in the core.

For transverse residual stresses, this phenomenon is even more pronounced, as comes out from figure 5. Altogether, the transverse residual stresses of the martensitic phase, in particular in the transition area to the HAZ, show higher absolute values than the longitudinal residual stresses. This indicates that the external shrinkage restraint of non-transforming, adjacent areas plays an important role in the development of residual stresses after completed cooling.

In principle, the residual stress distributions of the martensitic phase are qualitatively similar as a function of the chemical composition and, thus, of the $\mathrm{M}_{\mathrm{s}}$ - temperature. Differences arise particularly for the transverse residual stresses in the height of the compressive residual stresses at the boundary to the HAZ and at the tensile maximum in the weld centre, which in case of LTT filler with $8 \% \mathrm{Ni}$ showing the highest $\mathrm{M}_{\mathrm{s}}$ - temperature, represents as expected the peak value, since the mentioned quenching effects act here most strongly. In summary, it can be stated that the effects of the phase transformation discussed in the theory on lowering the residual stress level in the weld as well as the development of compressive residual stresses are actually existent.

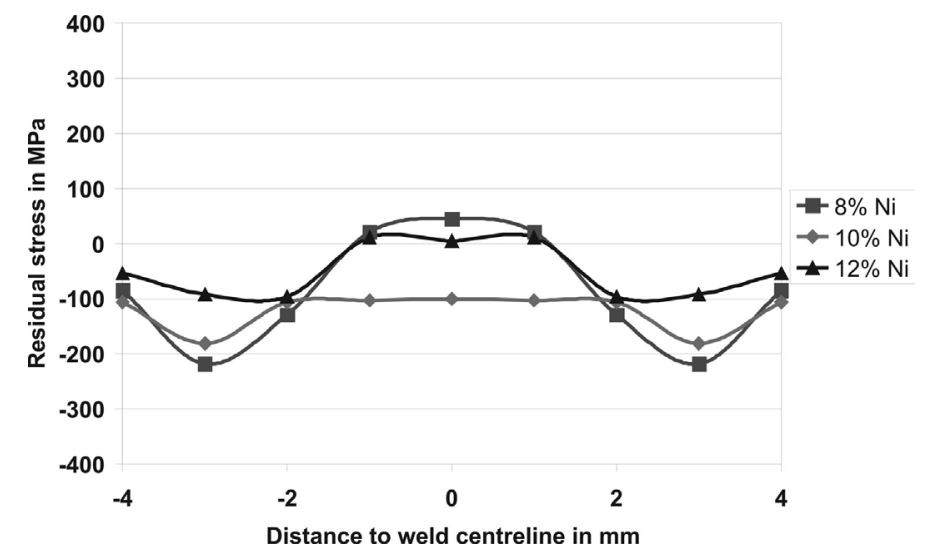

Figure 4. Phase specific longitudinal residual stresses in the martensitic phase depending on the Ni content of LTT filler material. 


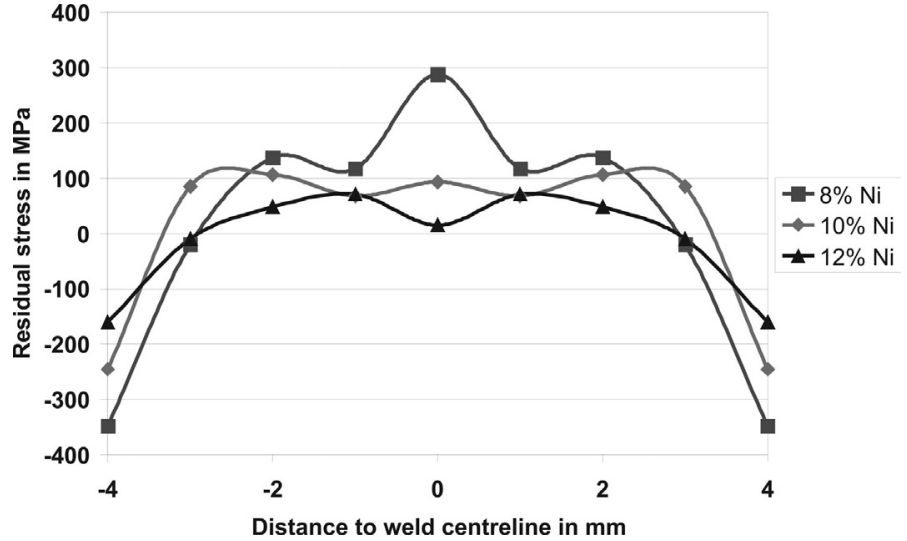

Figure 5. Phase specific transverse residual stresses in the martensitic phase depending on the Ni content of LTT filler material.

The austenitic phase shows more strongly fluctuating residual stress distributions (figures 6 and 7). While an LTT weld with $10 \% \mathrm{Ni}$ exhibits a nearly constant compressive residual stress distribution, welds with $8 \%$ and $12 \%$ Ni show more drastically varying distributions. The values vary here over the weld between positive and negative values. In contrast to the martensitic phase, this effect is more pronounced for the longitudinal residual stresses here. The lower the $\mathrm{M}_{\mathrm{s}}$ - temperature and the higher the associated contents of residual austenite, the higher the compressive residual stresses.

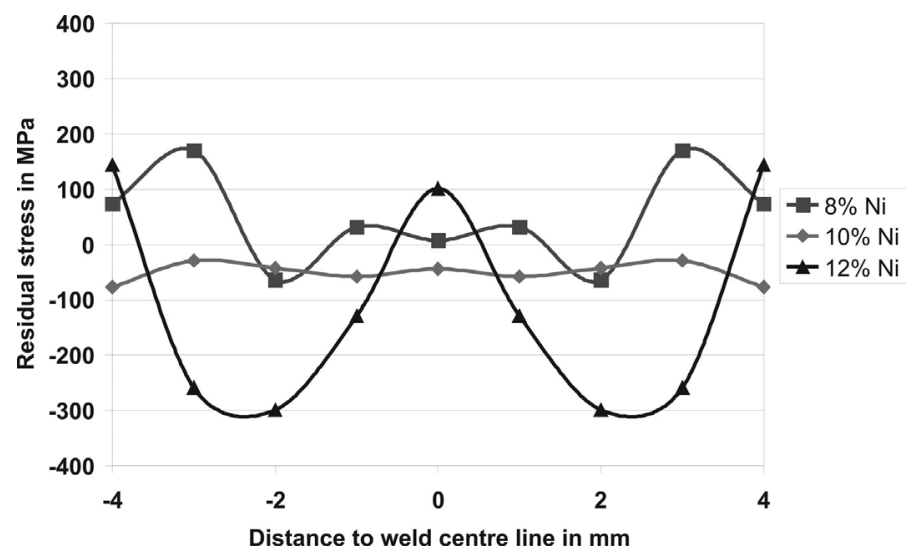

Figure 6. Phase specific longitudinal residual stresses in the austenitic phase depending on the Ni content of LTT filler material.

At lower transformation temperature, the influence of the phase transformation affects more the austenitic phase caused by an increase of its content. Thus, with increasing nickel content the transformation-specific compressive residual stresses develop more in the austenitic phase of the weld. This becomes particularly clear in figures 8 to 13 , in which the longitudinal and transverse residual stresses of the respective material are compared between both phases.

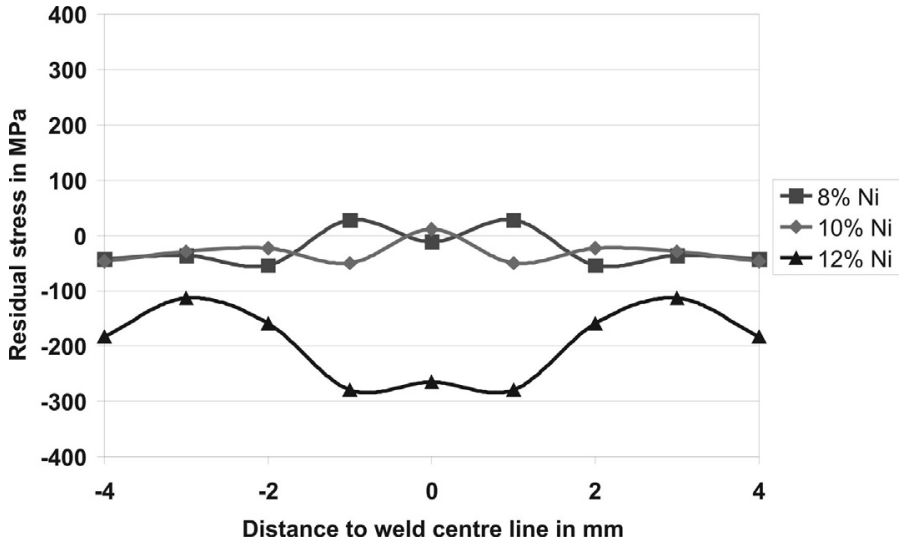

Figure 7. Phase specific transverse residual stresses in the austenitic phase depending on the Ni content of LTT filler material.

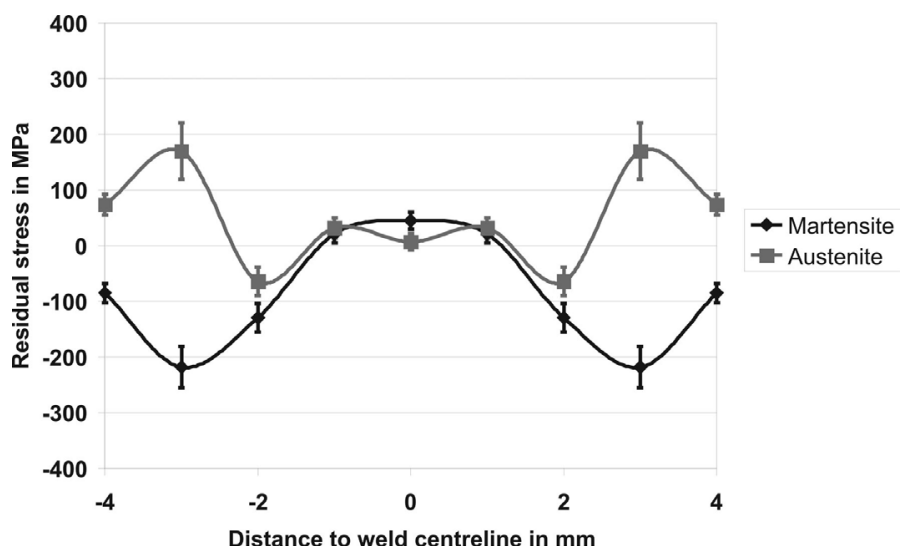

Figure 8. Phase specific longitudinal residual stresses in the martensitic and austenitic phase of LTT filler No. $1\left(8 \% \mathrm{Ni}, \mathrm{M}_{\mathrm{s}}\right.$ $\left.=184{ }^{\circ} \mathrm{C}\right)$.

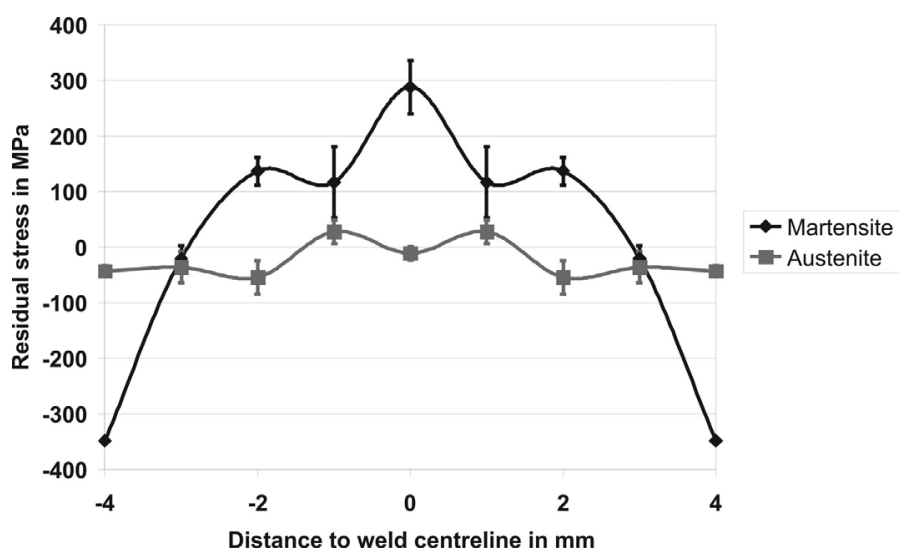

Figure 9. Phase specific transverse residual stresses in the martensitic and austenitic phase of LTT filler No. $1\left(8 \% \mathrm{Ni}, \mathrm{M}_{\mathrm{s}}\right.$ $\left.=184{ }^{\circ} \mathrm{C}\right)$.

Noticeable for the shown residual stress distributions is the qualitative similarity of the stress depth gradients of all three analyzed welding materials. In the weld centre, for example, all welds show the same sequence of the height of the residual stresses as a function of the evaluated diffraction line. Each diffraction line corresponds with a distinct mean penetration 
depth $\tau$. The higher the nickel content, the more pronounced the difference concerning the residual stress level. For example, the $220_{\alpha}$ diffraction in figure 16 shows a tensile residual stress level of about $800 \mathrm{MPa}$ in contrast to the $200_{\alpha}$ diffraction with compressive residual stresses of $-1100 \mathrm{MPa}$. However, the weighted mean of all evaluated diffraction lines leads to the phase specific residual stress, as shown in figure 4.

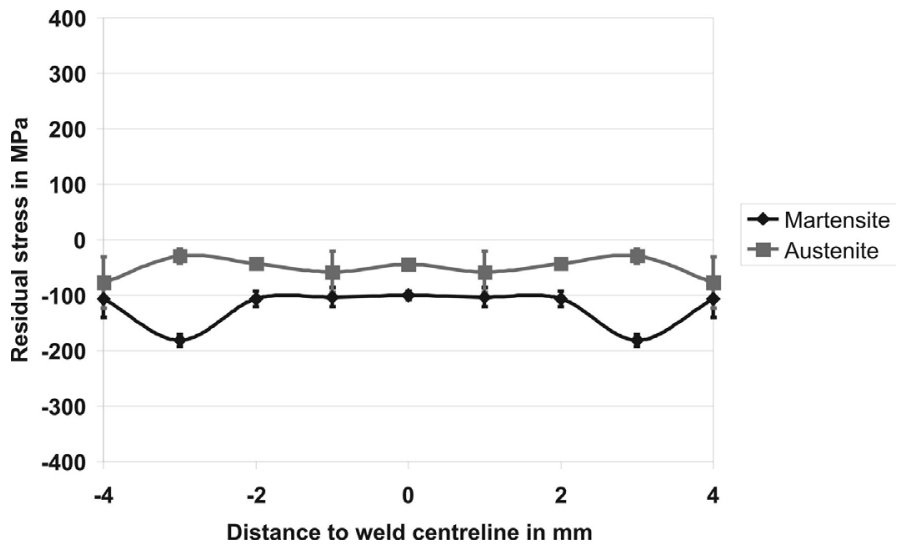

Figure 10. Phase specific longitudinal residual stresses in the martensitic and austenitic phase of LTT filler No. $2(10 \% \mathrm{Ni}$,

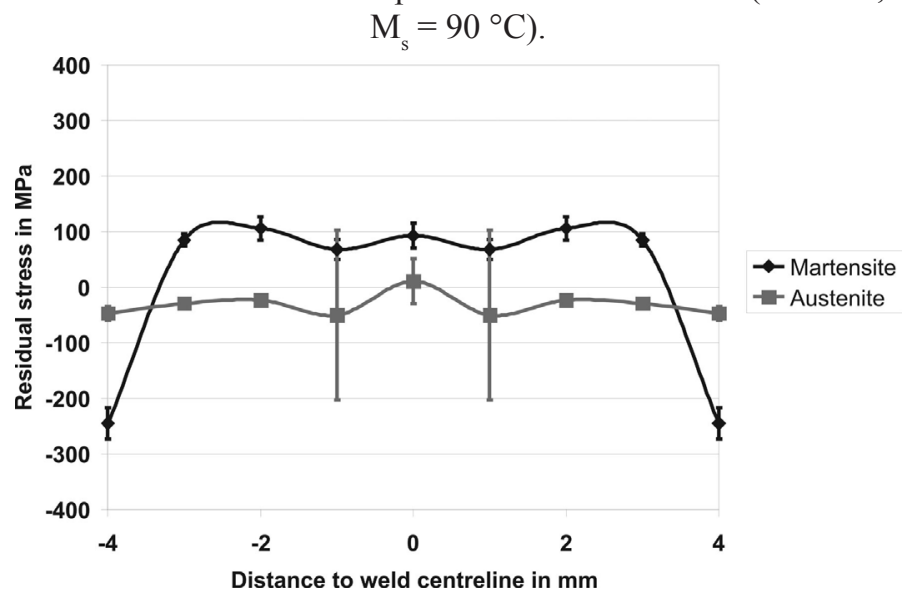

Figure 11. Phase specific transverse residual stresses in the martensitic and austenitic phase of LTT filler No. $2(10 \% \mathrm{Ni}$,

$$
\left.\mathrm{M}_{\mathrm{s}}=90^{\circ} \mathrm{C}\right) \text {. }
$$

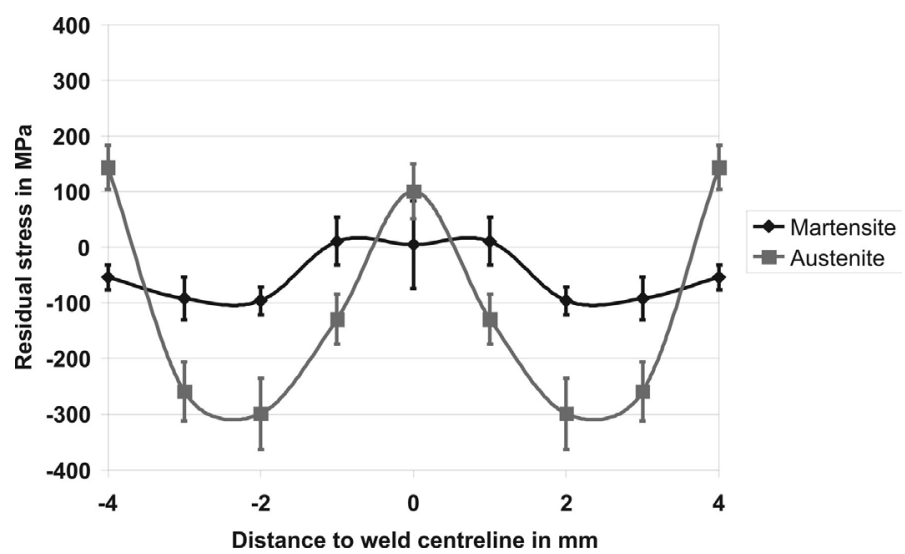

Figure 12. Phase specific longitudinal residual stresses in the martensitic and austenitic phase of LTT filler No. $3(12 \% \mathrm{Ni}$,

$$
\left.\mathrm{M}_{\mathrm{s}}=39^{\circ} \mathrm{C}\right) \text {. }
$$

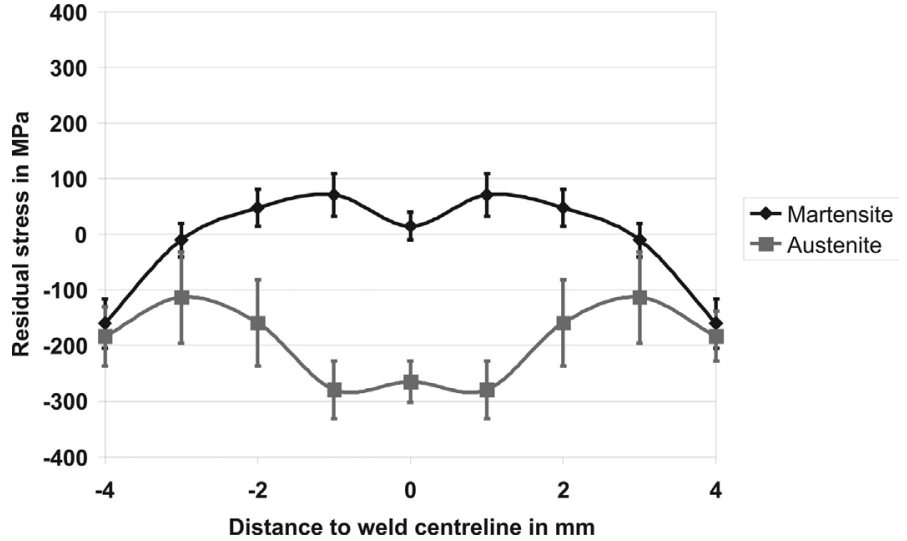

Figure 13. Phase specific transverse residual stresses in the martensitic and austenitic phase of LTT filler No. $3\left(12 \% \mathrm{Ni}, \mathrm{M}_{\mathrm{s}}=39^{\circ} \mathrm{C}\right)$.

Closer examination of the depth profiles of residual stresses in the martensitic phase, exemplarily represented for the longitudinal residual stresses of the welds in figures 14 to 16 , reveals a strong dependence of the residual stresses on the penetration depth. Since the mean penetration depth $\langle\boldsymbol{\tau}\rangle$ slightly varies across the weld, $\langle\boldsymbol{\tau}>$ is shown in the following diagrams as a depth range corresponding to the respective diffraction lines.

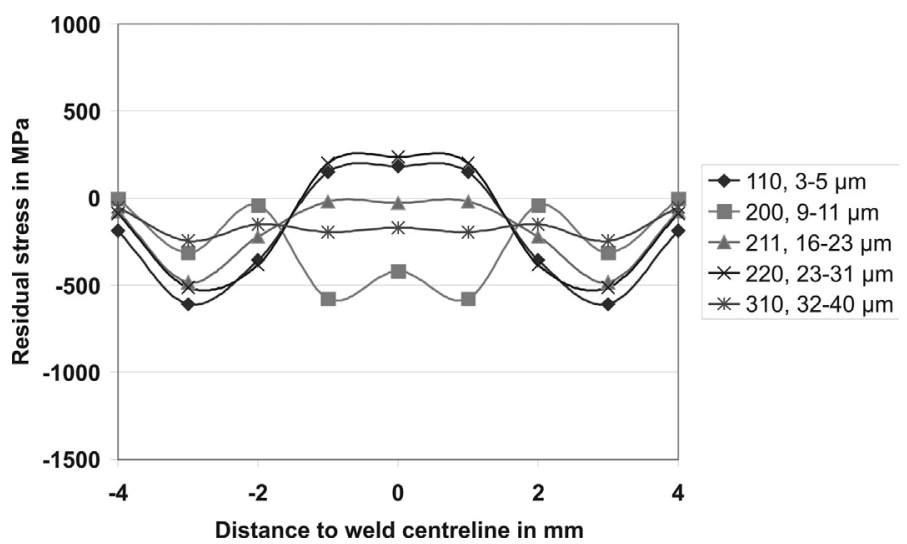

Figure 14. Phase specific longitudinal residual stresses in the martensitic phase of LTT filler No. $1\left(8 \% \mathrm{Ni}, \mathrm{M}_{\mathrm{s}}=184\right.$ ${ }^{\circ} \mathrm{C}$ ) depending on diffraction line and corresponding mean

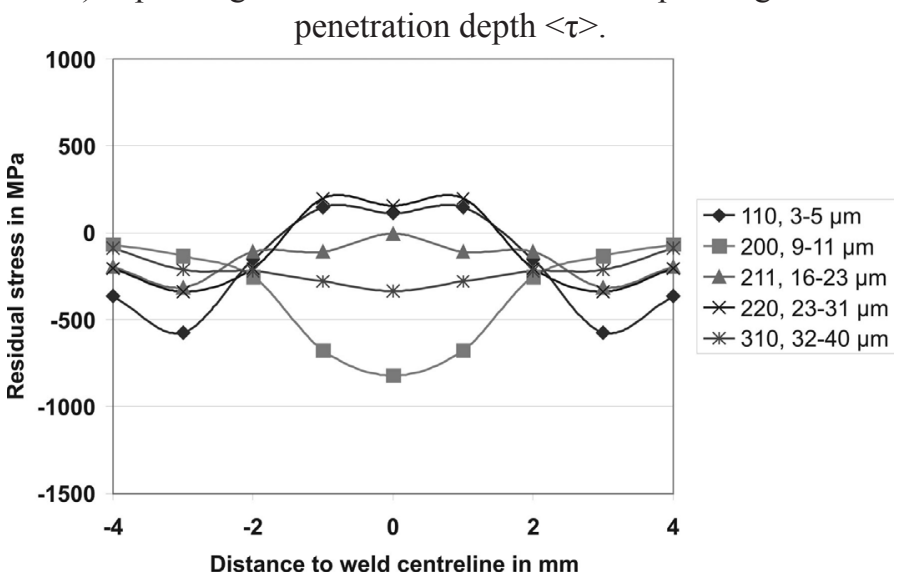

Figure 15. Phase specific longitudinal residual stresses in the martensitic phase of LTT filler No. $2\left(10 \% \mathrm{Ni}, \mathrm{M}_{\mathrm{s}}=90^{\circ} \mathrm{C}\right)$ depending on diffraction line and corresponding mean penetration depth $\langle\tau\rangle$. 


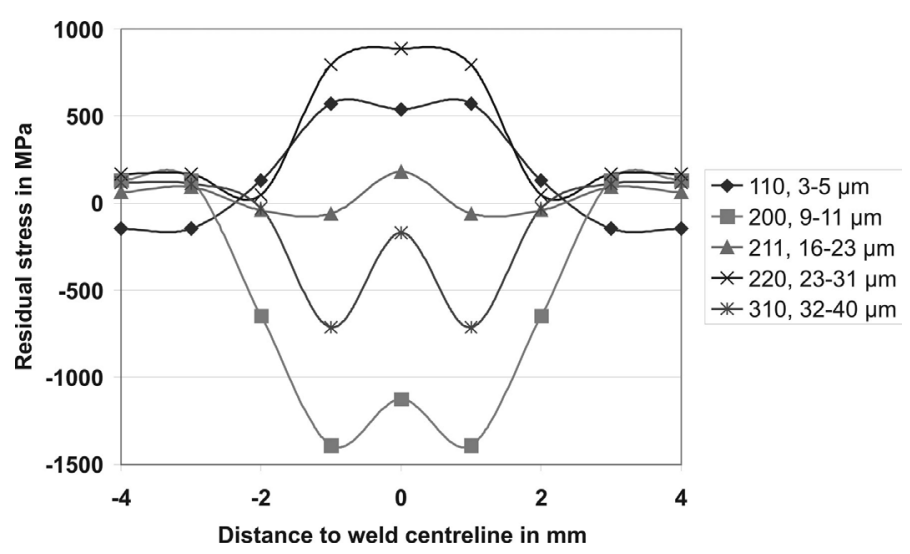

Figure 16. Phase specific longitudinal residual stresses in the martensitic phase of LTT filler No. $3\left(12 \% \mathrm{Ni}, \mathrm{M}_{\mathrm{s}}=39\right.$

${ }^{\circ} \mathrm{C}$ ) depending on diffraction line and corresponding mean penetration depth $\langle\tau>$.

An exact analysis of the residual stress depth profiles in the weld centre (figures 17 and 18) shows again the mentioned qualitative agreement of the residual stresses as a function of the nickel content and $\mathrm{M}_{\mathrm{s}}$ - temperature, respectively. At the same time, the residual stresses differ between tension and compression into the first $40 \mu \mathrm{m}$ before with increasing depth an almost zero-stress condition is reached.

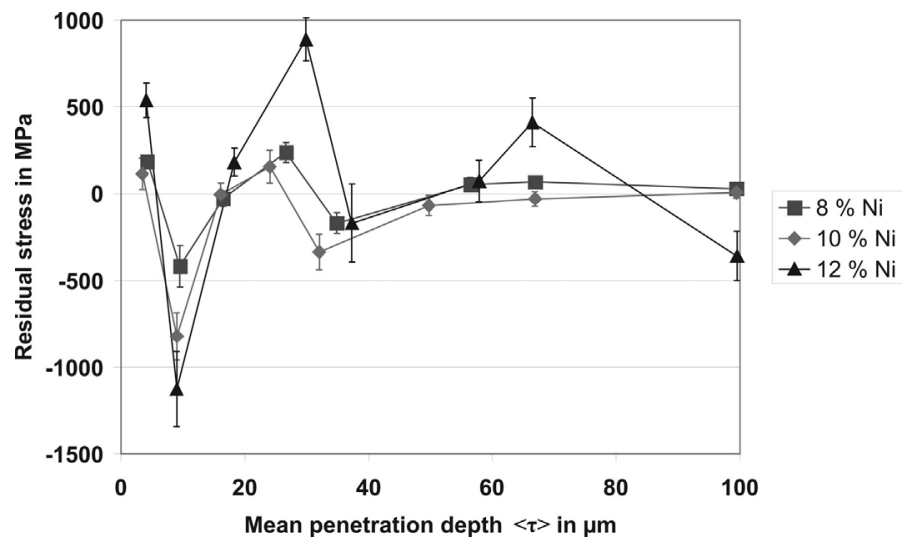

Figure 17. Phase specific longitudinal residual stress depth distribution of the martensitic phase depending on the $\mathrm{Ni}$ content of LTT filler material.

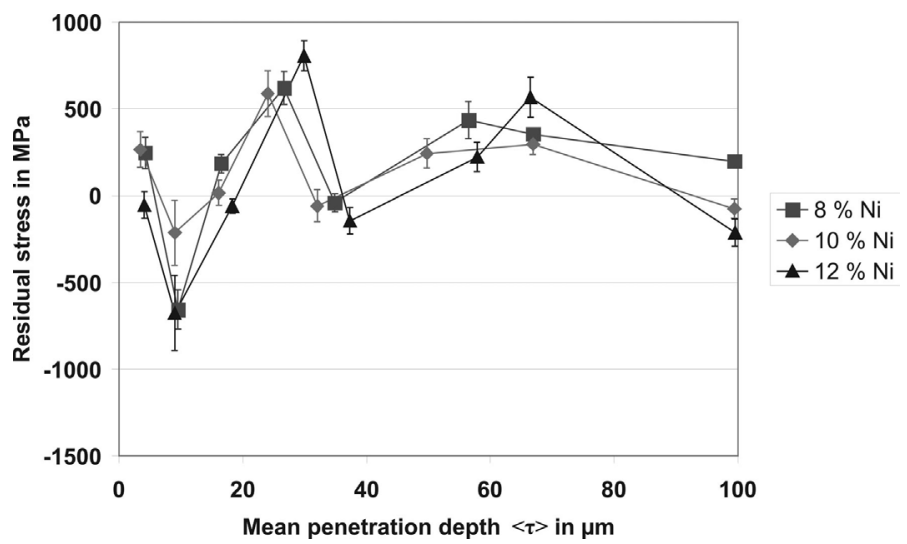

Figure 18. Phase specific transverse residual stress depth distribution of the martensitic phase depending on the $\mathrm{Ni}$ content of LTT filler material.
All three LTT weld materials examined here appear suitable for generating a reduction of the residual stresses in the weld area. An intended utilization of this result for purposes of fatigue resistance improvement or cold cracking avoidance, however, depends additionally strongly on the available mechanical properties. This issue has to be dealt with in future studies.

\section{Conclusions}

At the present state of investigations the following conclusions concerning residual stress formation during butt welding of S690 high strength steel with Low Transformation Temperature filler material can be drawn:

1. For the first time, residual stress distributions in Low Transformation Temperature (LTT) welding material could be assessed by use of high energy synchrotron radiation. This method was found to be successful in separating the phase-specific residual stresses of the involved martensitic and austenitic phase. Phase-specific residual stress depth gradients could additionally be assessed.

2. It becomes clear that compared to commercial high-strength filler materials, LTT-filler materials lead to a significant reduction of the residual stress level.

3. Dependent on chemical compositions and respective $M_{s}$ temperatures of the LTT fillers, characteristic residual stress distributions occur especially in the martensitic phase of the welds showing typical criteria of phase transformation influence. This applies for longitudinal as well as transverse residual stresses. The transverse residual stresses, the distribution shows greater alterations.

4. The residual stress distribution in the martensitic phase is qualitatively equal for different nickel contents, but stress peak values vary. The highest compressive residual stresses of up to $-350 \mathrm{MPa}$ were found at the boundary of the weld to the HAZ. At the same time, tensile residual stresses of about $300 \mathrm{MPa}$ arose at the weld centre.

5. The residual stress distribution in the austenitic phase is strongly influenced by the $M_{s}$ - temperature and by its content. At lower $\mathrm{M}_{\mathrm{s}}$ - temperature, the residual stress values of this phase show higher amounts of up to $-300 \mathrm{MPa}$.

6. The residual stress depth distributions of the investigated LTT welds show high fluctuations in the first $40 \mu \mathrm{m}$. Tensile as well as compressive residual stresses were discovered. These fluctuations are systematic and for all welds qualitatively equal. Highest fluctuations occurred in the weld centre. In depths of approx. $100 \mu \mathrm{m}$, an equal-zero-stress state was observed.

7. The investigated LTT materials are qualified for creating compressive residual stresses in the weld and HAZ by using the effect of martensite transformation at low temperatures. For evaluation of the residual stress state of LTT welds the coexisting martensitic and austenitic phases have to be taken into account. The macro residual stress state may also be influenced by the content of both phases. 


\section{Acknowledgments}

The authors would like to especially acknowledge Lincoln Electric Europe for provision of the welding consumables.

The authors are also grateful to Hahn-Meitner-Institute for performing measurements at the energy dispersive set-up of the HMI-beamline EDDI at Bessy site, Berlin.

\section{References}

[1] OHTA, A.; WATANABE, O.; MATSUOKA, K.; SHIGA, C.; NISHIJIMA, S.; MAEDA, Y.; SUZUKI, N.; KUBO, T. Fatigue Strength improvement by using newly developed low transformation temperature welding material, Welding in the World, 43, 6, p.38-42, 1999.

[2] SUZUKI, N.; OHTA, A.; MAEDA, Y. Repair of fatigue cracks initiated around box welds using low transformation temperature welding material. Welding International (2), p.112117, 2004.

[3] ZENITANI, S. et al.: Prevention of Cold Cracking in High strength Steel Welds by Applying Newly Developed Low Transformation-TemperatureWelding Consumables. $6^{\text {th }}$ INTERN. TRENDS IN WELDING RESEARCH CONFERENCE, 15.-19. April, 2002, Pine Mountain. Proceedings, Materials Park, OH: USA, 2003. p.569-574.

[4] MIKAMI, Y.; MOCHIZUKI, M.; TOYODA, M. In-Process Control of Weld Distortion by using Phase Transformation Effects, In: MATHEMATICAL MODELLING OF WELD PHENOMENA 8. Verlag der Technischen Universität Graz, eds. Cerjak, H.; Bhadeshia, H.K.D.H.; Kozeschnik, E., 2007, p.9811053.

[5] BHADESHIA, H.K.D.H.; Francis, J.A.; Stone, H.J.; Kundu, S.; Rogge, R.B.; Withers, P.J.; Karlsson, L.: Transformation Plasticity in Steel Weld Metals, 10th INTERNATIONAL AACHEN WELDING CONFERENCE, 24.-25. October, 2007, Aachen. Proceedings, Shaker Verlag, Aachen: Germany, 2007. p.171-179.

[6] KROMM, A.; KANNENGIESSER, TH.; GIBMEIER, J.; GENZEL, CH.; VAN DER MEE, V. Determination of Residual Stresses in Low Transformation Temperature (LTT-) Weld Metals using X-ray and High Energy Synchrotron Radiation, IIW - Doc. No. IIW-II-1658-07, 2007.

[7] MOCHIZUKI, M.; et al: Study of residual stress reduction in welded joints using phase transformation behaviour of welding material. Welding International, vol. 19, No.10, p.773$782,2005$.

[8] SHIGA, Ch.; BERNASOVSKY, P.; et al: Improvement of welded joints with low martensite transformation temperature weld consumables. Zvaranie-Svarovani, No.3, p.65-70, 2006.

[9] BHADESHIA, H.K.D.H.: Developments in Martensitic and Bainitic Steels: Role of the Shape Deformation. Materials Science and Engineering A, vol. A378, p.34-39, 2004.

[10] FRANCIS, J.A.; BHADESHIA, H.K.D.H.; WITHERS, P.J.: Welding residual stresses in ferritic power plant steels, Materials Science and Technology, vol. 23, no. 9, p.1009-1020, 2007.

[11] KROMM, A.; KANNENGIESSER, TH. In-situ-phase analysis using synchrotron radiation of low transformation temperature (LTT) welding material, 2008, submitted to Soldagem Insp.

[12] GENZEL, CH.; DENKS, I.A.; GIBMEIER, J.; KLAUS, M.; WAGENER, G. The materials science synchrotron beamline EDDI for energy-dispersive diffraction analysis, Nucl. Instrum. Methods in Phys. Research A 578, p.23-33, 2007.

[13] GENZEL, CH.; STOCK, C.; REIMERS, W.: Application of energy-dispersive diffraction to the analysis of multiaxial residual stress fields in the intermediate zone between surface and volume, Materials Science and Engineering A 372, 28-43, 2004.

[14] GENZEL, CH.; STOCK, C.; WALLIS, B.; REIMERS, W.: The application of white radiation to residual stress analysis in the intermediate zone between surface and volume, Nuclear Instruments and Methods in Physics Research A 467-468, p.1253-1256, 2001. 